\title{
Some practical results of the London Medical Group conference on iatrogenic disease
}

\author{
Sue Thorne and Andrew Herxheimer St Thomas' District Community Health Council and the Departments \\ of Pharmacology and Medicine, Charing Cross Hospital Medical School, London
}

Although many conferences stimulate a great deal of discussion and practical interest at the time, not so many are followed up to try and estimate what, if any, practical results followed the meeting. This the authors of this study have done. (In Britain the 'medical groups' are voluntary groupings of students at medical schools who meet to discuss ethical problems related to their profession.) Sixty-five participants (not all of them students) in the conference on iatrogenic disease replied to the questionnaire, and from the answers it was clear that not only the attitudes of those responding had in some cases been changed but in some positive action had resulted, for example, in the matter of prescribing.

This analysis may provide an answer to those who criticize conferences as being a waste of time and money, because much more than could be evaulated from the responses to this survey must have affected all the participants.

The 1975 London Medical Group (LMG) conference raised high expectations (all places were booked several weeks beforehand) and generated remarkable enthusiasm among the participants. An important reason was that Ivan Illich was to be one of the speakers. The audience was intensely involved in the topics discussed* and afterwards several people told us of important changes in their learning, teaching or practice that had followed the conference. This suggested that the conference might have had long-term effects on the thinking and behaviour of some of those who attended, and to obtain a clearer impression of the extent and variety of these effects we undertook a postal survey of those listed as participants. We hope that the results will interest and encourage others who are concerned about iatrogenesis.

\section{Method}

In February 1976, I I months after the conference, we wrote to the 400 people who had received tickets for it whose addresses we could trace. We asked them whether they had experienced any changes as

* The papers by Ivan Illich, Marshall Marinker, Edmond Leach and Katherine Whitehorn were published in this Journal (1975, I, 77-95). a result of attending the conference-in their learning, their teaching or in any other way-and to describe any such change in as much detail as they could. A reply-paid envelope was enclosed. Some of the letters to students were returned marked 'gone away', and it seems likely that others did not reach the addressees.

\section{Results}

Ten people wrote that they had not been able to attend the conference, but 65 who did replied to our questions; 33 of these were students (3I of them medical students from medical schools throughout the country), I 9 doctors and 13 other health workers.

\section{LEARNING}

Of the students, eight said that the conference had had no effect on them. The main effect for 228 students concerned their critical attitude towards modern medicine, particularly the use of drugs. Six of these students had been reassured that this attitude was legitimate; 16 had become more questioning as a result of the conference. Some had begun to question their teachers, others wished that they could do so. One student said: 'I find that I am prepared to argue with my peers more, put forward ideas to my superiors and take a more active part in discussions. During my introductory clinical course, we did have topic teaching sessions which enabled myself and others to question and think about certain issues'; and another: 'Medical courses are hardly renowned for their encouragement of free thinking. Examination syllabuses remain the same, irrespective of the title of the latest LMG conference. However I do find myself extremely sceptical of the claims made for various drugs. Whilst I have always been critical of the extensive use of drugs in the "treatment" of "mental illness", I think that last year's conference opened my eyes to the dangers, both mental and physical, involved in all drug treatment. These are far greater, I am sure, than is implied by the list of "side effects" that our lecturers slip in at the end of their eulogy of each particular drug, almost as an afterthought'.

Three students mentioned that they had been encouraged to do further reading; one of them said: ' $M y$ 2nd $M B$ course in sociology was continuing after I had attended the conference and read Medical Nemesis. The ideas on health autonomy put 
forward by Illich stimulated me to discuss newfound concepts and ideas with other medical students and my sociology lecturers. I also used Illich's ideas in answering a question on the doctor-patient relationship in our Part II exam'.

Five senior doctors thought they had not learnt anything at the conference, or had, but did not know what. Of three doctors who were 'already converted', one was rather exasperated by the conference, but two gained self confidence because they found others who thought as they did. Four mentioned a greater clarity about and awareness of autonomy and related issues in medicine. Other responses were: 'I am reading and thinking about ways in which groups may help the anxious, the isolated and the depressed'; 'I was stimulated to read Ivan Illich . . . and have incorporated some of his perspectives in my attitudes. The contributions by Katherine Whitehorn and Marshall Marinker made me appreciate the perspectives of an articulate and intelligent lay person'.

Of the non-medical health workers who said they learnt something, four were confirmed in their previous beliefs; one nurse tutor learnt a lot about autonomy, medical bureaucracy, the sick role; another gained a much broader perspective on health promotion and health care; a coordinator of nursing studies was made more aware of the side effects of proprietary preparations used for self medication. A dentist working in community dentistry, who was compiling a bibliography on iatrogenesis in relation to dentistry, has begun to write a review on the subject: the conference introduced him to names of authors new to him, and he followed these leads.

\section{TEACHING}

Six doctors reported changes in their teaching of medical students and postgraduates, including trainees in general practice. Two general practitioners gave greater emphasis to the dangers of treatment: 'the medical establishment, based as it is on "curative medicine", itself needs a powerful dose of new medicine called "resisting the urge to treat" , One of these also puts more effort into teaching patients self care. A psychiatrist stresses the need to get patients out of hospital quickly despite investigations, and to keep watching out for misleading and misinterpretable communications. One general practitioner now suggests to some patients that 'perhaps they'd be better off putting up with the illness'. Another has joined the committee of CURB (Campaign on Use and Restriction of Barbiturates); he has also stopped prescribing slimming pills and has started a slimming clinic.

Almost all of the non-medical health workers who responded said their teaching had been affected. Five who taught nurses used many of the concepts and topics discussed in the conference, eg, euthanasia, 'are hospitals for staff or for patients ?', change in the nature of disease, the nurse's responsibility to observe effects of treatment on patients, a lese dogmatic approach to teaching drug therapy.

The teacher of community dentistry is constantl using the concepts of iatrogenesis and autonomy in his teaching of students, and in postgraduate an public lectures.

A medical social worker and a senior pharmacis also reported effects on their teaching. An unex pected and powerful example of teaching was tha a union organizer had persuaded an administrato and a senior registrar to attend the conference. $A$ researcher in biological education who was collecting material on social biology for secondary-schoot teachers found the conference interesting ang useful. She regretted the lack of suitable materiat on the topics discussed that could be used in schools: 'It could make an excellent topic book fout Certificate of Secondary Education projects'.

\section{OTHER NEW ACTIVITIES AND ATTITUDES}

Sixteen students made other comments. Five. expressed their interest in discussing iatrogenesis? with others in small groups: one of these, a studen nurse, had set up the Health Autonomy Group a the end of the conference, and another student ha joined this. Four hoped that they would now have a better understanding of the patient as an individuate as a member of a family, and as a partner with ghe doctor in the management of his health care. Other points made were the importance of health edifia tion at a local level and its influence on the persontap use of minor analgesics and tranquillizers, greatem awareness of the structural and social iatrogenesis i psychiatry, the desirability of using drugs by thei approved names because this was cheaper, and of being less dependent on machines. One student was now thinking of doing community medicine and another microbiology. One had thought about giving up medicine as a result of the conference, bu now thought that it was better to change things from the inside.

A general practitioner became more critical of the use of tranquillizers, and more conscious of drug interactions. Another now tries harder to balances the good against the harm done by drugs. A young paediatrician notes: 'I must concentrate more ow how I get information across to patients and how $\vec{F}$ get information back from them'. Of two psychiae trists, one thinks more about helping people tou become less dependent on institutionalized life, the other is more wary of ideas of de-institutionalization which she had previously assumed were excellent.

One general practitioner has been more aware of autonomy-related issues in his private life, ie, with regard to his own and his family's health, and in general has been thinking about the topic of 'caring for each other', and at times doing it.

Two of the doctors had written several article and chapters for textbooks which were strikinglif 
influenced by having been at the conference. Two doctors joined in the study group already mentioned. This Health Autonomy Group met regularly for about six months and discussed many aspects of autonomy in the health field and related areas, such as industrial health and well being, housing, diet, stress. Specific topics included the role of the hospital environment (the effects of routines and of hospital architecture), and self medication. The group included several nurses and medical students, a general practitioner, two house officers, two dentists; a clinical pharmacologist and a social scientist working on drug dependence.

The senior pharmacist felt that his whole thinking and attitudes had been affected. The dentist had submitted evidence on iatrogenesis to the Parliamentary Sub-committee on Social Services; his attitudes to patients attending dentists had changed, and he had become very critical of the 'compliance' demanded by doctors and dentists.

A senior administrator concerned with research in the hospital service said he now felt more strongly the imbalance in western medicine between the clinical spectacular on the one hand, and primary care and service for the elderly and mentally disordered on the other hand; about the need to encourage people to attend more to self care and autonomy in health matters; and about the need to be constantly looking at the balance of allocation of resources between and within health services, environmental services and social services.

\section{Summary and conclusion}

Eleven months after the 1975 LMG conference on iatrogenic disease, 65 participants replied to our letter, most of them still enthusiastic about the varied effects of the conference on their learning, teaching or practice. Many of the students asked for a summary of the conference and of the results of this survey, and expressed an interest in discussions on iatrogenesis in small groups rather than in the more formal lecture situation of the conference hall.

Ideally such discussions would be part of the clinical course at all stages of undergraduate and postgraduate medical training, since issues of autonomy and self care need to be considered in every clinical situation. Two subjects that are particularly closely concerned with such issues are medical sociology and clinical pharmacology and therapeutics. What strikes us about the results of this survey is the remarkable range of effects the conference had on participants. For more than a few it was evidently a catalytic occasion, or even a conversion experience, that led to some long-term change in them. 